\title{
POLÍTICA EXTERNA, SEGURANÇA E DEFESA NOS GOVERNOS LULA E CARDOSO
}

Marcos Valle Machado da Silva

\begin{abstract}
Resumo
Este artigo tem como propósito analisar a Política Externa Brasileira nos temas de Segurança e Defesa, durante o governo do presidente Lula, comparando-o com o anterior, isto é, os dois mandatos do presidente Fernando Henrique Cardoso, a fim de identificarmos as continuidades, nuanças específicas, ou mesmo rupturas nesses temas. Para tanto, serão comparadas as ações dos governos em pauta em dois temas da agenda de Segurança e Defesa: Desarmamento e Controle de Armas Nucleares e Operações de Paz da Organização das Nações Unidas (ONU). Desse modo, pretendemos identificar traços de continuidade, ou mesmo de ruptura, na Política Externa Brasileira, nos temas supracitados, durante os governos dos dois últimos Chefes de Estado brasileiros.
\end{abstract}

Palavras-chave: Desarmamento e Controle de Armas Nucleares; Governos Lula e Cardoso; Operações de Paz; Política Externa Brasileira; Segurança e Defesa.

\begin{abstract}
This study analyses the Foreign Policy during the president Lula government over the Defense and Security issues, comparing these ones with the previous government of president Fernando Henrique Cardoso to identify de continuity, specifically nuances or even ruptures about these themes. To that aim we will use the United Nations Peacekeeping Operations and Nuclear Arms Control and Disarmament as Defense and Security themes. Thus we intend to identify the continuity traces or even rupture on the themes of Defense and Security of the Brazilian Foreign Police along the governments of the two last Brazilian Heads of State.
\end{abstract}

Keywords: Brazilian Foreign Police; Defense and Security; Cardoso and Lula Governments; Nuclear Arms Control and Disarmament, Peacekeeping Operations.

\section{Introdução}

Ao iniciar-se o ano 2010, vemos que o Brasil se encontra em um patamar distinto daquele da última década do século XX. Hoje vivemos em um país onde a democracia se consolidou, a estabilidade econômica é uma realidade, a redução das desigualdades sociais faz parte dos objetivos políticos de todos os partidos relevantes e, principalmente, da sociedade brasileira como um todo. Além disso, o Brasil assume um papel de protagonista nos principais temas da agenda internacional. Essa última característica é decorrente do somatório de todos os outros 
fatores que, em seu conjunto, moldaram a percepção externa quanto à relevância do Brasil no cenário internacional. Por outro lado, os formuladores e executores da nossa Política Externa têm atuado de forma usualmente hábil, explorando, quase sempre, com sucesso esse novo contexto. Assim sendo, a posição do Brasil nos temas afetos à agenda de Política e Segurança internacional tornou-se mais relevante para os demais atores internacionais.

Nesse contexto, este artigo tem como propósito analisar a Política Externa Brasileira nos temas de Segurança e Defesa, durante o governo do presidente Lula, comparando-o com o anterior, isto é, os dois mandatos do presidente Fernando Henrique Cardoso, a fim de identificarmos as continuidades, nuanças específicas, ou mesmo rupturas nesses temas. Para tanto, serão comparadas as ações dos governos em pauta em dois temas da agenda de Segurança e Defesa: Desarmamento e Controle de Armas Nucleares e Operações de Paz da Organização das Nações Unidas (ONU). Estes temas nos parecem adequados para uma avaliação, ainda que limitada, das posições políticas assumidas tanto pelo governo Fernando Henrique Cardoso quanto pelo governo Lula, acerca dos temas de Segurança e Defesa.

Assim sendo, iniciaremos o artigo com uma revisão teórica na qual serão abordados os conceitos de Segurança, Defesa e Defesa Nacional, bem como de Diplomacia e Política Externa, a fim de balizarmos o léxico utilizado no presente artigo. Em seguida será feita uma síntese das visões de mundo que nortearam a Política Externa dos governos Fernando Henrique Cardoso e Lula, evidenciando as diferenças entre elas. A seguir, utilizando-se as duas variáveis selecionadas, será efetuada uma análise parcial da visão da Política Externa Brasileira, nos temas afetos à Segurança e Defesa, durante os governos dos dois presidentes em pauta. Desse modo, pretendemos identificar traços de continuidade, ou mesmo de ruptura, na Política Externa Brasileira, nos temas supracitados, durante os governos dos dois últimos Chefes de Estado brasileiros. 


\section{Revisão Conceitual}

Julgamos pertinente apresentar a definição dos termos Segurança, Defesa e Defesa Nacional utilizando como referência a Política de Defesa Nacional (PDN) (BRASIL, 2005), revisada em 2005, uma vez que esse é o documento condicionante de mais alto nível do planejamento de Defesa e tem por finalidade estabelecer objetivos e diretrizes para o preparo e o emprego da capacitação nacional, com o envolvimento dos setores militar e civil, em todas as esferas do Poder Nacional.

É importante destacar que a PDN, tem como premissas os fundamentos, objetivos e princípios dispostos na Constituição Federal e encontra-se em consonância com as orientações governamentais e a Política Externa do país, a qual se fundamenta na busca da solução pacífica das controvérsias e no fortalecimento da paz e da Segurança internacionais.

A PDN considera que a Segurança pode ser enfocada a partir do indivíduo, da sociedade e do Estado, do que resultam definições com diferentes perspectivas. Em linhas gerais, a Segurança é a condição em que o Estado, a sociedade ou os indivíduos não se sentem expostos a riscos ou ameaças, enquanto que Defesa é ação efetiva para se obter ou manter o grau de segurança desejado. As medidas que visam à Segurança são de largo espectro, envolvendo, além da defesa externa: defesa civil; segurança pública; políticas econômicas, de saúde, educacionais, ambientais e outras áreas, muitas das quais não são tratadas por meio dos instrumentos político-militares.

Assim, nesse artigo, tal qual na PDN, serão adotados os seguintes conceitos para Segurança, Defesa e Defesa Nacional:

I - Segurança é a condição que permite ao País a preservação da soberania e da integridade territorial, a realização dos seus interesses nacionais, livre de pressões e ameaças de qualquer natureza, e a garantia aos cidadãos do exercício dos direitos e deveres constitucionais;

II - Defesa é a ação efetiva para se obter ou manter o grau de Segurança desejado; e 
III - Defesa Nacional é o conjunto de medidas e ações do Estado, com ênfase na expressão militar, para a defesa do território, da soberania e dos interesses nacionais contra ameaças preponderantemente externas, potenciais ou manifestas.

Do mesmo modo, julgamos pertinente apresentar algumas considerações acerca dos termos Diplomacia e Política Externa, uma vez que expressam idéias distintas, porém, algumas vezes são utilizados, equivocadamente, como sinônimos. Assim sendo, nesse artigo, utilizaremos os seguintes conceitos para Diplomacia e Política Externa:

I - "A Diplomacia compreende a ação externa dos governos expressa em objetivos, valores e padrões de conduta, vinculados a uma agenda de compromissos pelos quais se pretende realizar determinados interesses" (CERVO, 2008, p. 8).

II - A expressão Política Externa "representa o canal através do qual as políticas e estratégias internacionais de um Estado são formuladas, executadas e avaliadas, ou seja, a Política Externa é a estratégia da Diplomacia" (GONÇALVES e SILVA, 2005, p. 186). Em síntese, a Política Externa provê o conteúdo da Diplomacia (CERVO, 2008).

Feitas essas considerações conceituais, abordaremos, ainda que sumariamente, as visões de mundo que nortearam a Política Externa dos governos Fernando Henrique Cardoso e Lula, visando identificar os respectivos modelos de inserção internacional dominantes nesses dois governos. Essa abordagem nos parece adequada, pois diferentes visões de inserção internacional implicam em matizes específicos, ou mesmo em descontinuidades, na Política Externa, incluindo os temas afetos à agenda de Segurança e Defesa.

\section{Política Externa do Governo Cardoso - Visão Liberal Híbrida}

Na década de 1990, o liberalismo ressurgiu tanto como programa político quanto como paradigma das relações internacionais. A estrutura do sistema internacional alterou-se da bipolaridade para um momento unipolar, como decorrência do fim da Guerra Fria, da desintegração da União das Repúblicas Socialistas Soviéticas (URSS) e da vitória do 
modelo Ocidental, liderado pelos Estados Unidos da América (EUA). Nesse contexto, os temas da agenda internacional foram dominados pela disseminação da democracia e do liberalismo de mercado. Paralelamente; houve uma aparente revitalização da ONU, como fórum de Segurança coletiva, materializada na coalizão montada contra o Iraque em 1990-1991. Do mesmo modo, ocorreu uma revalorização e o favorecimento de instituições internacionais, bem como a crença de que a globalização ${ }^{1}$ transformaria a política mundial, alterando o significado da soberania dos Estados. Em síntese, todos esses fatores impregnaram a visão de inserção internacional de uma expressiva parcela de políticos e formuladores de Política Externa brasileiros (HURRELL, 2009).

Eleito presidente da República em 1994, Fernando Henrique Cardoso iniciou seu governo em janeiro de 1995, sendo reeleito em 1998, para um segundo mandato que terminou em 2002. Ao longo dos seus dois mandatos, a Política Externa brasileira pode ser descrita como estruturada em quatro eixos centrais: a ênfase no multilateralismo, o avanço da integração regional, isto é, o Mercosul; diversificação de parceiros nas relações bilaterais; e esforços para elevar o Brasil a membro permanente do Conselho de Segurança das Nações Unidas (CSNU) (VIZENTINI, 2005).

Economicamente, ao lado da estabilidade proporcionada pelo Plano Real, o governo Cardoso promoveu a abertura, ainda que controlada, do mercado nacional aos produtos $e$ investimentos estrangeiros, bem como iniciou o desmonte do Estado empresário, por meio de um programa de privatizações de empresas estatais. O ideário liberal de Estado reduzido e maior liberdade individual, ou seja, dos mercados, bem como de valorização das instituições intergovernamentais, permeou o primeiro mandato do governo Cardoso.

\footnotetext{
${ }^{1}$ Termo entendido, neste artigo, como designando os vários processos de integração, em nível global, "nas áreas política, econômica, cultural e social, motivados em grande medida por avanços tecnológicos (especialmente no âmbito das comunicações), com efeitos transformadores de tempo e espaço para as experiências humanas" (GONÇALVES e SILVA, 2005, p. 82).
} 
No que tange à Política Externa, os reflexos desse modelo manifestaram-se na adesão brasileira aos principais Regimes ${ }^{2}$ internacionais. No entanto, ainda na década de 1990, percebeu-se aquilo que uns poucos já tinham visto: o capitalismo neoliberal, impulsionado pela globalização, não estava trazendo o mundo de felicidade para os Estados que se abriram aos seus encantos. A globalização e o pensamento neoliberal estavam aumentando as desigualdades entre Estados ricos e pobres, assim como a desigualdade interna dentro de cada Estado, incluindo os desenvolvidos. Esse contexto conduziu a um encontro entre os principais governantes identificados, ou pertencentes à Social Democracia, denominado Progressive Governance for the XXI Century, realizado em Florença (1999), reunindo Bill Clinton, Tony Blair, Lionel Jospin, Massimo D’Alema, Gerhard Schröder e Fernando Henrique Cardoso.

Nesse encontro, os governantes reunidos tentaram alinhavar uma política social-democrata comum, que conciliasse a lógica do mercado com as necessidades sociais internas de cada país. No entanto, a agenda social-democrata lá concebida, continuou sem resolver as demandas sociais que estavam em processo de ascensão nesses países, particularmente no Brasil.

Em síntese, a visão de mundo do governo Cardoso, implicou na busca da inserção internacional mediante a adesão aos principais Regimes internacionais, enfatizando o multilateralismo, promovendo a abertura do mercado nacional e a redução do tamanho do Estado. Paralelamente, quase que como um seguro contra os possíveis efeitos de uma globalização percebida como assimétrica, aprofundou-se a integração regional e conservou-se a regulação da economia por parte do Estado. Desse modo, a visão do governo Cardoso pode ser

2 Entendidos aqui, tal como definidos por Stephen Krasner, isto é, "como um conjunto implícito ou explícito de regras, normas, princípios e procedimentos de tomada de decisão, ao redor do qual as expectativas dos atores internacionais convergem em uma área de interesse" (KRASNER apud GONÇALVES e SILVA, 2005, p. 211). Sob essa ótica, os regimes internacionais existem "para criar cenários propícios ao exercício da negociação internacional, bem como para viabilizar acordos e cooperação de longo alcance" (GONÇALVES e SILVA, 2005, p. 212). 
identificada, tal como apontada por Amado Cervo, como a de um neoliberalismo híbrido (CERVO, 2008, p. 53).

\section{Política Externa do Governo Lula - Visão Próxima do Paradigma Realista}

A transição do governo Cardoso para o governo Lula representou tanto uma mudança de partido governante quanto de ideologia no poder, podendo ser entendida como uma transição de um liberalismo híbrido para um governo de esquerda, igualmente híbrido (CERVO, 2008). Essa mudança também correspondeu à passagem da visão liberal, para uma posição muito mais próxima do paradigma realista das relações internacionais. Em síntese, operou-se a transição da crença de que as negociações internacionais baseadas nas Instituições e no Direito Internacional estabeleceriam regras justas e aceitas por todos os Estados, para uma visão realista baseada na reciprocidade das relações interestatais, bem como no fortalecimento da América do Sul como pólo de poder e plataforma política e econômica de realização dos interesses brasileiros (CERVO, 2008).

A ideologia subjacente à Política Externa do governo Lula, segundo Amado Cervo (2008), associa um elemento externo, o liberalismo, a outro interno, o desenvolvimentismo. Desse modo, concebe uma estratégia de relações internacionais, cuja ação se agrega à das Estruturas Hegemônicas do poder, entendendo que o país delas deve fazer parte. Cabe aqui uma digressão conceitual acerca das Estruturas Hegemônicas. O Embaixador Samuel Pinheiro Guimarães, um dos formuladores da Política Externa do governo Lula, aponta que hoje não existe um Estado claramente hegemônico, pois a estrutura do sistema internacional apresenta uma unipolaridade militar (EUA); uma multipolaridade econômica (EUA, União Européia, Japão e China) e um condomínio político exercido pelos membros permanentes do Conselho de Segurança das Nações Unidas (GUIMARÃES, 2007). Assim, utiliza a expressão Estruturas Hegemônicas para designar a realidade do sistema internacional e seus complexos mecanismos de dominação. Apesar de 
não ser claramente explicitado, o autor em pauta, dedica todo um capítulo de sua obra Quinhentos Anos de Periferia a esse constructo.

Entendemos o conceito de Estruturas Hegemônicas como o ordenamento ou estruturação do sistema internacional nas esferas político, militar, econômica e ideológica, tendo como centro as Grandes Potências, as quais têm à frente os EUA (GUIMARÃES, 2007). Ainda com relação às proposições do Embaixador Samuel Pinheiro Guimarães, é pertinente destacar aquilo que ele aponta como o objetivo estratégico dos Grandes Estados Periféricos, qual seja: "[...] participar dessas Estruturas Hegemônicas, de forma soberana e não-subordinada, ou reduzir seu grau de vulnerabilidade diante dessas Estruturas" (GUIMARÃES, 2007, p. 161).

Assim, mesmo enfatizando as relações multilaterais, tal qual o governo Cardoso, a política Externa do governo Lula apresenta uma outra concepção da ação multilateral, que transita da ênfase na acomodação aos Regimes internacionais para a participação ativa da produção de regras e normas desses Regimes, isto é, atuar como parte dos Estados que conformam a agenda internacional. O propósito maior, ou efeito desejado é o de penetrar nas "Estruturas Hegemônicas" do poder, "de modo a ser parte do jogo de reciprocidades internacionais", bem como "do comando e dos benefícios" dela decorrentes (CERVO, 2008, p. 103).

\section{Política Externa Brasileira e a Agenda de Segurança e Defesa}

Feitas as considerações sumárias acerca das respectivas visões de inserção internacional dos governos Fernando Henrique Cardoso e Lula, passaremos para análise da Política Externa desses dois governos, nos dois temas afetos à agenda de Segurança e Defesa por nós selecionados para a análise proposta neste artigo, isto é: o Desarmamento e Controle de Armas Nucleares e as Operações de Paz da ONU. 


\section{Desarmamento e Controle de Armas Nucleares}

Durante o governo do presidente Fernando Henrique Cardoso, a Política Externa brasileira teve como propósito inserir o Brasil nos Regimes internacionais de Desarmamento e Controle de Armas, com destaque para o Regime de Não-Proliferação de Armas Nucleares. É importante destacar que essa política apresenta continuidade com o governo anterior, do presidente Itamar Franco, quando o Brasil assinou ou ratificou sua adesão aos seguintes Tratados e Acordos de Desarmamento: em 1993, o governo brasileiro assinou a Convenção sobre Armas Químicas e a Proibição de Armas Biológicas; em 1994, tendo como Chanceler ${ }^{3}$ o Embaixador Celso Amorim, adotou as diretrizes do Regime de Controle de Tecnologia de Mísseis (MTCR) e; ainda em 1994, aderiu ao Tratado de Tlatelolco ${ }^{4}$ que proscreve as armas nucleares na América Latina (CERVO, 2008).

Assim, a adesão do Brasil ao Tratado sobre a Não-Proliferação de Armas Nucleares (TNP), assinada pelo presidente Fernando Henrique Cardoso em 13 de julho de 1997, na presença do então Secretário-Geral das Nações Unidas, Kofi Annan e, posteriormente, ratificada pelo Congresso Nacional, em 1998, culminou o processo de amadurecimento da posição brasileira no tocante à não-proliferação de armas nucleares ${ }^{5}$.

Na mesma ocasião, o presidente também assinou o instrumento de ratificação brasileira ao Tratado de Proibição ampla de Testes nucleares (CTBT - Comprehensive Nuclear Test Ban Treaty). Ainda que

\footnotetext{
3 O Embaixador Celso Amorim foi Ministro das Relações Exteriores no período de 21 de maio de 1993 até o término do mandato do presidente Itamar Franco, em 01 de janeiro de 1995 (VIZENTINI, 2005).

4 É pertinente destacar que o Brasil assinou e ratificou o Tratado de Tlatelolco em 1967, com o respectivo instrumento de ratificação depositado em 29 de janeiro de 1968. No entanto, algumas Resoluções aprovadas posteriormente (as resoluções são aprovadas por maioria de dois terços entre os signatários do Tratado), durante a década de 1990 particularmente a Resolução 290, de 26 de agosto de 1992, que apresentou uma emenda no artigo 16 desse Tratado, não foram assinadas e ratificadas pelos governos brasileiro e argentino. Essa Resolução determinava o direito irrestrito da Agência Internacional de Energia Atômica (AIEA) de executar inspeções forçadas nos Estados signatários. Somente após o acordo Quadripartite é que o Brasil e a Argentina se ajustaram ao previsto nessa nova cláusula. Sendo esse o motivo do Tratado só vigorar nos dois países após as respectivas assinaturas e ratificações da emenda em pauta, o que ocorreu em 1994, por parte dos dois governos (BRASIL, 1994).

5 O depósito do instrumento de adesão do Brasil ao TNP foi feito no dia 18 de setembro de 1998, simultaneamente em Washington, Londres e Moscou (UNODA, 1998).
} 
esses instrumentos apenas formalizassem compromissos que, conforme será exposto mais adiante, já haviam sido assumidos pelo Brasil no que tange à não-proliferação nuclear, o ato teve grande importância política, uma vez que representou o enquadramento definitivo do Brasil no Regime de Não-Proliferação de Armas Nucleares (LAFER, 2006).

Cabem aqui mais algumas considerações sobre o TNP, haja vista que a adesão a esse Tratado é objeto de críticas, por vezes desprovidas de um conhecimento mínimo sobre o mesmo. O TNP foi aberto para assinatura em 1968 e entrou em vigor em 1970, sendo concebido com o propósito de parar a proliferação das armas nucleares, no ponto em que ela se encontrava em 1968, dividindo os Estados signatários em duas categorias: os Estados nuclearmente armados e os Estados nãonuclearmente armados. Os Estados pertencentes à primeira categoria são definidos, pelo Tratado, como aqueles que efetuaram uma explosão nuclear antes de 01 de janeiro de $1967^{6}$, ou seja, EUA, a Rússia ${ }^{7}$, Reino Unido, França e China. Assim sendo, o TNP define todos os demais Estados como não-nuclearmente armados. Apesar do caráter intrinsecamente discriminatório, o TNP mostrou-se extremamente atrativo para muitos dos Estados ditos não-nuclearmente armados, em função daquilo que se tornou conhecido como sendo a barganha básica do TNP, qual seja: em troca do compromisso dos Estados nãonuclearmente armados abdicarem do desenvolvimento e aquisição das armas nucleares, bem como se submeterem às salvaguardas internacionais destinadas a verificar esse compromisso ${ }^{8}$, os Estados nuclearmente armados se comprometem facilitar o mais amplo intercâmbio possível de equipamento, materiais e informação científica e tecnológica sobre a utilização da energia nuclear para fins pacíficos ${ }^{9}$, bem como engajar em negociações de desarmamento visando a

\footnotetext{
${ }^{6}$ Artigo IX - parágrafo 3 (NAÇÕES UNIDAS NO BRASIL, s./d.).

7 A Rússia substituiu a URSS no status de Estado nuclearmente armado, em 1992, ao passo que a Ucrânia, Belarus e o Cazaquistão desistiram de suas armas nucleares herdadas com a dissolução da URSS, concordando com o status de Estados nãonuclearmente armados (CIRINCIONE, WOLFSTHAL e RAJKUMAR, 2002).

${ }^{8}$ Artigo II do TNP (NAÇÕES UNIDAS NO BRASIL, s./d.).

${ }^{9}$ Artigo IV do TNP (NAÇÕES UNIDAS NO BRASIL, s./d.).
} 
completa eliminação de seus arsenais nucleares ${ }^{10}$. Os EUA, Rússia e o Reino Unido servem como Estados depositários do tratado, sendo Estados-parte desde a sua vigência em 1970. Já a China e a França se tornaram Estados signatários apenas em 1992. É importante destacar que os cinco Estados nuclearmente armados, reconhecidos pelo TNP, não se tornaram signatários deste tratado de modo simultâneo. A adesão da China e da França ao tratado, somente em 1992, aponta que o TNP tal como concebido na década de 1960, refletia uma tentativa de congelamento do poder nos moldes percebidos como mais seguros para os EUA e a URSS. Essa situação não se coadunava com os interesses da China e da França que, mesmo tendo o status de Estados nuclearmente armados, percebiam o TNP como um instrumento que cercearia sua soberania quanto às decisões de exportar ou não tecnologia nuclear, inclusive a de aplicação bélica, para outros países.

Atualmente, o tratado tem 183 Estados membros nãonuclearmente armados, de um total de 188 participantes. Somente Israel, Índia e Paquistão são não-signatários do tratado, situação acrescida pela República Democrática Popular da Coréia (RDPC) que se retirou do TNP em 2003. Deste modo, é perceptível que o TNP é hoje o tratado de controle de armas com maior adesão na história, contendo também, em seu Artigo VI, o compromisso de um futuro desarmamento nuclear. Isso decorre da alteração da percepção acerca desse tratado por parte dos Estados, principalmente após o término da Guerra Fria. É significativo que, no período compreendido entre dezembro de 1991 e setembro de 1998, quarenta e três Estados tornaram-se signatários do TNP ${ }^{11}$, refletindo que o TNP passou a ser percebido como um instrumento que pode conduzir a um incremento da segurança e da estabilidade mundial. Além disso, o grande mérito do TNP foi, ao longo dos anos, converter o que era um motivo de orgulho nacional (a

\footnotetext{
${ }^{10}$ Artigo VI do TNP (NAÇÕES UNIDAS NO BRASIL, s./d.).

11 UNITED NATIONS. Status of Multilateral Arms Regulation and Disarmament Agreements. NPT. Disponível em: <http://disarmament.un.org/TreatyStatus.nsf $>$. Acesso em: 19 nov. 2010.
} 
aquisição de armas nucleares) em um ato considerado contrário às práticas do mundo civilizado.

A adesão do Brasil ao TNP não acarretou nenhum esforço de inspeções adicional àquele de que já éramos objeto em decorrência do Acordo Quadripartite ${ }^{12}$, um típico acordo de salvaguardas abrangentes, igual em todos os seus aspectos aos acordos que os Estados signatários do TNP são obrigados a concluir com a Agência Internacional de Energia Atômica (AIEA). Assim, as duas usinas nucleares - Angra I e II -, os reatores de pesquisa existentes no país e todas as instalações do programa nuclear brasileiro, incluindo aquelas destinadas ao enriquecimento de Urânio, estavam em conformidade com as salvaguardas da AIEA, desde 1994, ano em que entrou em vigor o acordo Quadripartite. O ingresso no TNP fortaleceu esses compromissos e habilitou o Brasil a participar de maneira mais credenciada e eficaz, no âmbito dos mecanismos estabelecidos pelo TNP, bem como dos esforços internacionais em prol do desarmamento nuclear. A adesão ao TNP deixou clara a opção da política externa brasileira em favor do Regime internacional de Não-Proliferação de Armas Nucleares, o que reforça nossas credenciais para seguir reivindicando, com toda a legitimidade e sem interesses velados, a eliminação completa das armas nucleares por parte dos Estados nuclearmente armados. Deste modo, o Brasil está inserido no Regime em pauta, em consonância com o previsto em nossa Constituição ${ }^{13}$, sendo importante frisar que no atual contexto global, em que o paradigma da Não-Proliferação é posto em questão, Brasil e Argentina aparecem como casos exemplares de aumento da percepção de Segurança, por meio da cooperação.

Durante o governo Lula reapareceram divergências acerca da participação brasileira no Regime de Não-Proliferação de Armas

12 O Brasil firmou com a Argentina, em agosto de 1991, o Acordo para o Uso Exclusivamente Pacífico da Energia Nuclear, que criou a Agência Brasileiro-Argentina de Contabilidade e Controle de Materiais Nucleares (ABACC). Em seguida, os dois países firmaram um acordo com a ABACC e a Agência Internacional de Energia Atômica (AIEA) para a Aplicação de Salvaguardas, conhecido como Acordo Quadripartite, que entrou em vigor em março de 1994 (ALMEIDA e MARZO, 2006).

${ }^{13}$ A Constituição brasileira, em seu título III, artigo 21, inciso XXIII, alínea a, determina que "toda atividade nuclear em território nacional somente será admitida para fins pacíficos e mediante aprovação do Congresso Nacional" (BRASIL, 2009). 
Nucleares, principalmente, no que tange à adesão ao Protocolo Adicional do TNP. Este Protocolo amplia o leque de salvaguardas, visando assegurar a ausência de materiais ou atividades nucleares clandestinas, mediante a expansão das atividades de fiscalização e controle da AIEA. Considerado, corretamente, como intrusivo, o governo brasileiro, bem como o argentino, não o assinaram. É importante destacar que o Estado brasileiro apresenta um histórico ilibado no que tange à Não-Proliferação de Armas Nucleares e que qualquer incremento nas salvaguardas já implementadas no país, dependerá da ação efetiva por parte dos Estados reconhecidos como nuclearmente armados, em prol do cumprimento do Artigo VI do TNP, isto é, ações efetivas de redução dos seus arsenais nucleares.

Uma das possíveis críticas à adesão brasileira ao TNP é a de ao assinar e ratificar esse tratado, o governo brasileiro renunciou a um recurso de poder. Nada mais falacioso, pois renunciar ao desenvolvimento e à posse de armas nucleares é completamente diferente de renunciar à tecnologia nuclear. Nenhum governo brasileiro, minimamente responsável, poderia renunciar à tecnologia nuclear, incluindo o domínio do ciclo de enriquecimento de Urânio. O Brasil domina essa tecnologia, em escala laboratorial, desde a década de 1980, e hoje, em 2010, essa tecnologia está sendo implementada em escala industrial na Fábrica de Combustível Nuclear (FCN), localizada no município de Resende, no estado do Rio de Janeiro. Assim, não renunciamos a nenhum recurso de poder, mas consolidamos um dos fatores da Segurança da nação brasileira, ao assinarmos o mencionado Acordo Quadripartite, que eliminou a possibilidade de uma corrida por armas nucleares entre o Brasil e a Argentina. Equacionada essa questão, de maneira racional, não haveria porque não aderir a um Tratado, no qual está alicerçado o Regime de Não-Proliferação de Armas Nucleares e, em relação ao qual cumpríamos, desde 1994, todas as salvaguardas dos seus signatários. Tal posicionamento reforçou a credibilidade e o capital diplomático brasileiro nos fóruns multilaterais, principalmente na questão do Desarmamento e da Não-Proliferação Nuclear, onde o Brasil e a Argentina despontam como exemplos a seguir. 
Sintetizando, no tema afeto ao Desarmamento e Controle de Armas Nucleares, observa-se a continuidade da Política Externa brasileira, no governo Lula, em relação ao governo Cardoso. Cabendo destacar que a recusa em assinar o Protocolo Adicional do TNP é coerente com a visão realista da política externa do atual governo, baseada na reciprocidade das relações interestatais, tanto nas relações bilaterais quanto nos fóruns multilaterais, incluindo os diversos Regimes internacionais em que o Brasil está inserido.

\section{Operações de Paz}

Passaremos agora para a análise da Política Externa brasileira nos temas afetos à agenda de Segurança e Defesa, dos governos Cardoso e Lula à luz do segundo tema por nós selecionado: as Operações de Paz das Nações Unidas. Membro fundador da ONU, o Brasil participa das Operações de Paz das Nações Unidas, desde 1956, quando participou da I Força de Emergência das Nações Unidas (United Nations Emergency Force - UNEF I), na Faixa de Gaza (SOUZA e ZACCARON, 2006).

Durante o governo Cardoso, o Brasil teve uma participação destacada nas operações de Paz, integrando, entre outras, a Missão da ONU em Angola (UNAVEM III - United Nations Angola Verification Mission III). Para esse país foram enviados contingentes sucessivos, de cerca de 1.300 militares brasileiros em cada um deles ${ }^{14}$, sendo essa a maior força militar brasileira no exterior desde a $2^{a}$ Guerra Mundial. Cabe destacar que esses contingentes foram desdobrados com meios logísticos exclusivamente brasileiros, isto é, sem apoio de nenhuma outra Potência. O Brasil também participou com forças policiais na Operação de Paz das Nações Unidas no Timor Leste, em 1999.

Além das missões supracitadas, o governo brasileiro enviou observadores militares para países da América Central, tais como El Salvador e Guatemala. Também durante o governo Cardoso, o Brasil participou da MOMEP (Military Observer Mission Ecuador-Peru), para

\footnotetext{
14 Entre 1995 e 1997, o governo brasileiro enviou um total de 4.222 homens (militares e policiais) para a UNAVEM III (SOUZA e ZACCARON, 2006).
} 
auxiliar na solução do conflito fronteiriço entre Equador e Peru. Além disso, integrou duas operações para a retirada de minas terrestres no âmbito da Organização dos Estados americanos (OEA): MARMINAS (Missão de Assistência para Remoção de Minas na América do Sul), no Equador e no Peru, e MARMINCA (Mission for Assistance with the Removal of Mines in Central America), na Nicarágua, Honduras e Guatemala (SOUZA e ZACCARON, 2006).

O período de aprendizado e acúmulo de experiências em Operações de Paz, na década de 1990, possibilitou o aperfeiçoamento contínuo dos militares brasileiros nesse tipo de operação. Nesse contexto, podemos perceber que o convite formulado ao Brasil para comandar a Missão de Estabilização das Nações Unidas no Haiti ${ }^{15}$ (MINUSTAH - United Nations Stabilization Mission in Haiti) não é um mero acaso, mas sim o resultado de uma Política Externa consciente e contínua dos governos brasileiros, acerca dessa questão.

Assim, no primeiro semestre de 2004, um contingente de cerca de 1.200 militares brasileiros foi desdobrado no Haiti. Com a MINUSTAH ainda em curso, o governo Lula reafirma o compromisso da Política Externa brasileira com o multilateralismo, com a busca de soluções pacíficas dos conflitos (internos e externos), bem como a disposição de cooperar em prol da Segurança internacional. Com essa ação de longa duração, o país aufere credibilidade perante os demais Estados membros das Nações Unidas, o que contribuí para reforçar o projeto de um futuro assento permanente no CSNU (SOUZA e ZACCARON, 2006).

Ao observarmos a prática dos oito anos do governo Cardoso e de quase igual período de governo Lula, percebemos que a participação do Brasil em Operações destinadas a contribuir para a paz e a segurança internacionais, permite que o país possa se projetar no âmbito global como ator relevante no principal fórum multilateral de segurança coletiva, isto é, a ONU. Em outras palavras, o Brasil deseja ter credenciais para se manifestar em temas afetos à Segurança

15 Estabelecida em 01 de junho de 2004, por meio da Resolução 1542 do CSNU (MINUSTAH, 2004). 
internacional, mesmo não tendo um poder militar significativamente expressivo em termos de capacidade de intervenção global.

Finalizando esse tópico, podemos apontar que existe continuidade na Política Externa Brasileira, nos temas afetos à agenda de Segurança e Defesa, à luz da análise na participação das Operações de Paz das Nações Unidas. Cabe, no entanto, ressaltar que a participação na longa missão do Haiti tem sido explorada com habilidade pela diplomacia brasileira, na consecução do objetivo maior de inserção dentro da Estruturas Hegemônicas do sistema internacional.

\section{Considerações Finais}

Entendemos que o ponto de convergência central da Política Externa, concebida e implementada por meio da Diplomacia, dos dois governos, nos temas relacionados à agenda de Segurança e Defesa, aqui analisados, é a ênfase no multilateralismo. É consenso entre os nossos formuladores de Política Externa que o plano multilateral é favorável à geração de poder, ao passo que o plano bilateral é propício ao emprego e aplicação do poder, isto é, nele afloram as assimetrias entre os atores envolvidos. Portanto, é racional empreender esforços na valorização e participação ativa nas instituições internacionais para, por um lado, promover seus interesses pontuais e, por outro, engajar as Grandes Potências em ambientes institucionalizados. É inegável que as organizações intergovernamentais funcionam como locus onde os países emergentes podem exercer alguma influência, uma vez que as regras e procedimentos dessas instituições limitam a liberdade de ação dos países mais poderosos (HURRELL, 2009). A questão do multilateralismo aparece como um elemento de continuidade marcante na Política Externa do governo Lula. Porém, apresenta o diferencial de buscar a reciprocidade e relações igualitárias entre Estados, principalmente nas relações com os EUA.

No que tange às questões de segurança e Defesa, a Política Externa do governo Lula, à luz das variáveis selecionadas, apresenta claros elementos de continuidade com o governo anterior, com algumas mudanças de ênfase, tal como a atuação ativa na busca de assento 
permanente no CSNU e a firme posição de não assinar o Protocolo Adicional, até que os Estados Nuclearmente Armados demonstrem que estão interessados em cumprir o Artigo VI do TNP. Com base na análise dos dois temas explorados, ainda que de forma sucinta, percebemos que a continuidade supracitada marca uma posição coerente com uma significativa parcela do pensamento diplomático brasileiro que, mesmo latente no governo Cardoso, esteve presente na contribuição à formulação e execução da Política Externa brasileira. Nos pontos analisados também percebemos que a Política Externa do governo Lula, não à política externa do $P T$, mas sim a do Brasil, consonante com as posições já existentes no Itamaraty. A Política Externa implementada pelo governo Lula busca, efetivamente, reduzir nossas vulnerabilidades frente às Estruturas Hegemônicas e, se possível, participar delas.

Finalizando, consideramos que a Política Externa brasileira, nos temas relacionados à Segurança e Defesa, nos governos dos presidentes Fernando Henrique Cardoso e Lula, apresenta nítidos pontos de convergência, ou seja, de continuidade. As diferenças, comentadas ao longo do artigo, não podem ser caracterizadas como rupturas. Em nosso entendimento elas são decorrentes das visões de mundo dos dois presidentes em pauta, e seus respectivos partidos. Assim, a política Externa executada pelos dois governos, nos dois temas abordados, aponta para a convergência de propósitos, com ênfases distintas na dinâmica para alcançá-los.

No entanto, é pertinente repetir que nossa análise é parcial, fruto da seleção de apenas dois entre diversos temas da agenda de Segurança e Defesa. Para uma análise mais acurada, outros temas, tais como Segurança Regional, Política de Defesa Nacional, bem como Estratégia Nacional de Defesa em vigor, poderiam ser utilizadas para evidenciar de forma mais completa as convergências, rupturas e diferenças pontuais da Política Externa colocada em prática, nos temas afetos à Segurança e Defesa, pelos dois governos aqui abordados. Apesar dessa limitação, entendemos que o artigo apresentado serve como estímulo acadêmico para estudos mais aprofundados da questão aqui abordada. 
Marcos Valle Machado da Silva é Capitão-de-Fragata (RM-1), Mestrando do Programa de Pós-Graduação em Estudos Estratégicos (PPGEST), da Universidade Federal Fluminense (UFF).

E-mail: mbvalle2002@yahoo.com.br

\section{Referências:}

ALMEIDA, Silvio Gonçalves de; MARZO, Marco Antônio Saraiva. A Evolução do Controle de Armas Nucleares. Rio de Janeiro: Ciência Moderna, 2006.

BRASIL. Ministério das Relações Exteriores. Tratado de Tlatelolco. 1994. Disponível em: <http://www2.mre.gov.br/dai/tlatelolco.htm>. Acesso em: 20 nov. 2010.

BRASIL. Ministério da Defesa. Publicações. Política de Defesa Nacional. O Estado, a Segurança e a Defesa. 2005. Disponível em: <https://www.defesa.gov.br/index.php/publicacoes/politica-de-defesanacional.html>. Acesso em: 19 nov. 2010.

BRASIL. Senado Federal. Constituição da República Federativa do Brasil. Texto consolidado até a Emenda Constitucional no 61 de 11 de novembro de 2009.2 Disponível em: <http://www.senado.gov.br/sf/legislacao/const>. Acesso em: 20 nov. 2010.

CERVO, Amado Luiz. Inserção Internacional: formação dos conceitos brasileiros. São Paulo: Saraiva, 2008.

CIRINCIONE, Joseph; WOLFSTHAL Jon B.; RAJKUMAR, Miriam. Deadly Arsenals: Tracking Weapons of Mass Destruction. Washington, DC: Carnegie Endowment for International Peace, 2002.

GONÇALVES, Williams; SILVA, Guilherme A. Dicionário de Relações Internacionais. Barueri: Manole, 2005.

GUIMARÃES, Samuel Pinheiro. Quinhentos anos de periferia: uma contribuição ao estudo da política internacional. Rio de Janeiro: Contraponto, 2007.

HURRELL, Andrew. Ensaio analítico. O Brasil e os Estados Unidos: reflexões comparativas. In: HIRST, Monica. Brasil - Estados Unidos: desencontros e afinidades. Rio de Janeiro: Editora FGV, 2009. p. 167229. 
LAFER, Celso. Comércio, desarmamento, direitos humanos - reflexões sobre uma experiência diplomática. 2. ed. São Paulo: Paz e Terra, 2006.

MINUSTAH. United Nations Stabilization Mission in Haiti. 01 jun. 2004. Disponível

em:

<http://www.un.org/en/peacekeeping/missions/minustah/>. Acesso em: 19 nov. 2010.

NAÇÕES UNIDAS NO BRASIL. Tratados. Tratado Sobre a NãoProliferação de Armas Nucleares. s./d. Disponível em: <http://www.onu-brasil.org.br/doc_armas_nucleares.php>. Acesso em: 27 nov. 2010.

SOUZA, André Matheus; ZACCARON, Beatriz Ávila. A participação do Brasil em Missões de manutenção de paz: o caso do Haiti. In: BRIGADÃO, Clóvis; PROENÇA, Domício Jr. O Brasil e os novos conflitos internacionais. Rio de Janeiro: Gramma, 2006. p. 211-230.

UNODA. United Nations Office for Disarmament Affairs. Status of Multilateral Arms Regulation and Disarmament Agreements. NPT. 18 sep. $1998 . \quad$ Disponível em: <http://disarmament.un.org/TreatyStatus.nsf>. Acesso em: 19 nov. 2010.

VIZENTINI, Paulo Fagundes. Relações Internacionais do Brasil - de Vargas a Lula. 2. ed. São Paulo: Perseu Abramo, 2005. 